\title{
HYPOGLYCAEMIC COMA
}

\author{
BY \\ P. HEBERDEN and F. FRIEDLANDER \\ From the Transvaal Memorial Hospital for Children and the Department of Paediatrics, \\ University of the Witwatersrand, Johannesburg
}

(RECEIVED FOR PUBLICATION JANUARY 28, 1955)

Symptoms of hypoglycaemia have only been recognized since the introduction of insulin. Since that time they have been noted in connexion with syndromes other than the over-production and overdosage of insulin, and the symptom-complex has become a well recognized entity. Most of these nonpancreatic causes of hypoglycaemia do not lead to coma. A low blood sugar level may be found in Addison's disease, Simmonds disease and myxoedema and in conditions of chronic hepatic insufficiency, in malnutrition, and following prolonged, severe exercise. In von Gierke's disease there is a lowered blood sugar level, although the patient rarely complains of symptoms relative to hypoglycaemia.

The pancreatic causes of hypoglycaemia are (a) tumours of the islet tissue, and (b) the condition of hyperinsulinism; the hypoglycaemia in both these conditions may be sufficiently severe to precipitate the patient into coma. During the stabilization and maintenance of insulin therapy such episodes often occur and occasionally may lead to crippling mental or physical sequelae.

Finally, overdosage of insulin will cause hypoglycaemia as exemplified in our case which is reported here.

\section{Case Report}

L.W., a white child aged 2 years and 1 month, was admitted in coma to the Transvaal Memorial Hospital for Children on April 30, 1953. The child was a diabetic and was well controlled on 10 to 15 units of N.P.H. insulin each morning. Since her discharge from hospital six weeks before, when her insulin dosage had been stabilized, she had developed and recovered from a mild diarrhoea and upper respiratory tract infection.

The mother stated that she had felt that the child would be cured of her diabetes if she remained sugar-free for a period of time. She had consequently increased the insulin dosage above the prescribed level and had at the same time restricted the child's diet. The child had been irritable for some time and had tended to become inattentive and 'dreamy'; the mother had also noted that this was worse before meals. This querulousness and inability to concentrate had become worse in the few days before admission, although it was not attended by signs other than occasional twitching of the left hand for three days before admission. This state of affairs culminated in the parents finding the child unconscious early one morning. Before admission to this hospital the child had been unconscious for 17 hours in another hospital where initially insulin had been given and intravenous glucose administered later, but no control blood sugar estimations done. The child had been energetically treated for 'shock', this including the application of hot-water bottles to secure warmth.

On examination the child was deeply comatose with involuntary movements of the left face, arm and leg. The face and hand twitched continuously, whilst the leg was less affected. The urine was sugar-free.

All other systems were clear.

Examination of the cerebrospinal fluid excluded other central nervous system conditions, such as encephalitis. The physical findings, combined with such a definite history of insulin overdosage, were so typical that a diagnosis of hypoglycaemic coma was made, despite the finding of a normal blood sugar level after admission, which it was felt, was due to the intravenous administration of glucose before admission.

A full blood examination on the day of admission gave the following results: Haemoglobin $15 \mathrm{~g}$., erythrocytes $5,000,000$, leucocytes 14,500 , blood sugar level $202 \mathrm{mg}$. \%, serum potassium level $19.2 \mathrm{mg} . \%$, and serum sodium level $283 \mathrm{mg}$. \%. Four hours after admission the blood sugar level was $324 \mathrm{mg} . \%$, and 12 hours after admission it had fallen to $122 \mathrm{mg} . \%$. On May 1 the cerebrospinal fluid was examined, when no cells were seen, protein was $10 \mathrm{mg}$. \%, chloride $700 \mathrm{mg}$. \% (as $\mathrm{NaCl}$ ) and sugar $66 \mathrm{mg} . \%$

On admission an intravenous infusion of isotonic saline was begun and $40 \mathrm{ml}$. of $50 \%$ solution of glucose administered intravenously. On receipt of the laboratory reports insulin was also given. Insulin dosage was guided by the amount of sugar in the urine, tested fourhourly. During the first 60 hours a total of $500 \mathrm{ml}$. of normal saline and $1,000 \mathrm{ml}$. of $5 \%$ dextrose in normal saline and $2,000 \mathrm{ml}$. of $5 \%$ dextrose in water was given (Fig. 1). Vitamin B1, 1,000 mg., and vitamin C, $100 \mathrm{mg}$., were added daily to the infusion.

On the third day cortisone therapy was instituted in 
TABLE 1

DETAILS OF TREATMENT

\begin{tabular}{|c|c|c|c|c|c|c|}
\hline Day & $\begin{array}{l}\text { Insulin } \\
\text { (units) }\end{array}$ & $\begin{array}{l}\text { Cortisone } \\
\text { (mg.) }\end{array}$ & $\begin{array}{l}\text { Vitamins } \\
\text { (units) }\end{array}$ & $\begin{array}{l}\text { Penicillin } \\
\text { (units) }\end{array}$ & Sedation & $\begin{array}{l}\text { Fluids } \\
\text { (ml.) }\end{array}$ \\
\hline 1 & 10 & Nil & Nil & 400,000 & Nil & 500 \\
\hline 2 & 10 & Nil & 1,000 Vit. $\left.B_{1}\right\}$ & do. & Nil & $\begin{array}{c}\text { normal saline } \\
1,000\end{array}$ \\
\hline 3 & 5 & 50 & $\begin{array}{l}100 \text { Vit. C } 5 \\
\text { do. }\end{array}$ & do. & Phenobarbitone & $\begin{array}{l}5 \% \text { dextrose/normal saline } \\
2,500\end{array}$ \\
\hline 4 & 26 & 50 & do. & do. & $\begin{array}{l}\text { gr. } 11 \\
\text { do. }\end{array}$ & $5 \%$ dextrose in water \\
\hline $\begin{array}{l}5 \\
6 \\
7\end{array}$ & $\begin{array}{l}16 \\
16 \\
22\end{array}$ & $\begin{array}{l}40 \\
30 \\
20\end{array}$ & $\begin{array}{l}\text { do. } \\
\text { do. } \\
\text { do. }\end{array}$ & $\begin{array}{l}\text { do. } \\
\text { do. } \\
\text { do. }\end{array}$ & $\begin{array}{l}\text { do. } \\
\text { do. } \\
\text { Nil }\end{array}$ & $\begin{array}{c}5 \% \text { dextrose/water } \\
\text { do. } \\
\text { do. } \\
\text { Oral fluids }\end{array}$ \\
\hline
\end{tabular}

view of its glycogenic properties, and $50 \mathrm{mg}$. was given daily for two days and then decreased by $10 \mathrm{mg}$. daily (Table 1).

From the sixth day the level of consciousness improved and the jerking grew less. The child at this stage responded to painful stimuli. By the eighth day she was fully conscious, but extremely irritable and still mani-

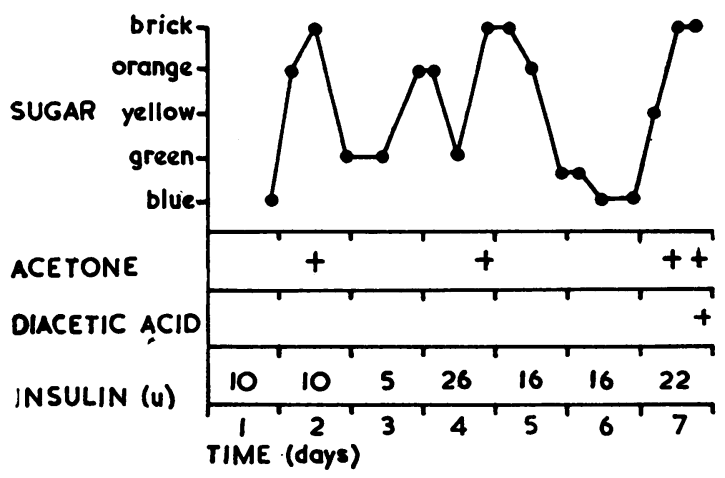

Fig. 1.-Chart of urine analysis.

fested occasional twitching of the left arm, hand and leg. It was noted at this time that the patient could not use the left arm and that the left leg was weak.

The child remained in hospital for a further three months during which time a gradual improvement in the left facial palsy and the left leg were noted. The left arm, however, did not improve as much and on her discharge from hospital she still had a considerable paralysis of this limb. During this time the left arm and leg twitched almost daily, but no loss of consciousness was associated.

An air-encephalogram (Fig. 2) was performed on July 27 and Dr. H. Jackson reported that there was dilatation of the right lateral ventricle with displacement to the right. This suggested right cerebral atrophy.

The child has now been followed for 18 months since admission, and this period has seen worsening of the fits. At first they took the form of jerks of the arm, but gradually she started to manifest absences and about 12 months after admission to hospital, akinetic seizures began to make their appearance. Major epilepsy is also present, but these attacks are not as frequent. Attacks of one or other type of epilepsy occur up to 20 times a day, the child falls frequently, and is never without evidences of trauma.

She appears lethargic and the mother has noted that she cerebrates slowly and has learned very few new words since her discharge from hospital. During the early phase of recovery she spoke very little. The mother feels that there is definite mental retardation. The left hemiplegia remains stationary and there is also a degree of dysarthria which shows itself in a thick, slurred speech.

The diabetes remains as before, but she is reasonably well controlled on 10 units crystalline insulin and 10 units P.Z. insulin each morning combined with a free diet.

A Merrill-Palmer intelligence test was given and the following results were obtained:

$$
\begin{aligned}
& \text { Chronological age .. } \quad \text {.. } 3 \text { years } 8 \text { months } \\
& \text { Mental age .. } \quad . . \quad \text {.. } 2 \text { years } 3 \text { months } \\
& \text { I.Q. . . } \quad \ldots \quad \ldots \quad \text {. } \quad 61
\end{aligned}
$$

During the test the child was extremely distractable; she was unable to give her full attention to the test. When presented with a test item, she was vague as to

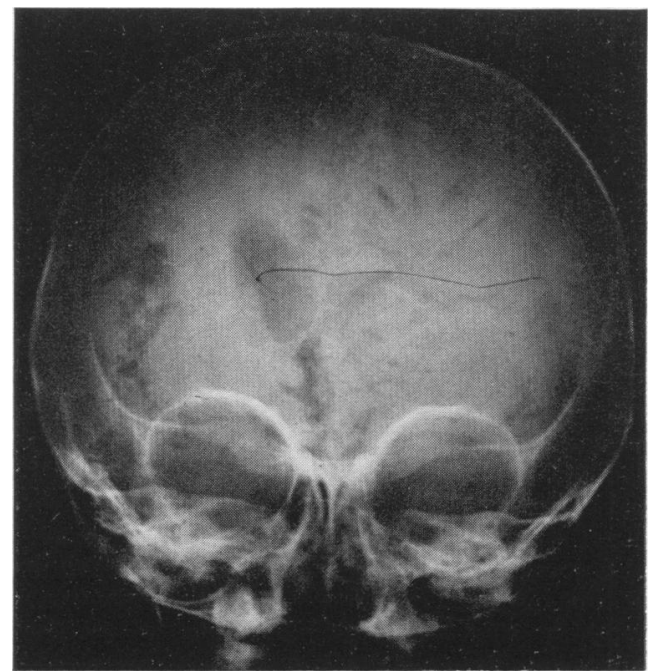

FIG. 2.-Postero-anterior air encephalogram. 


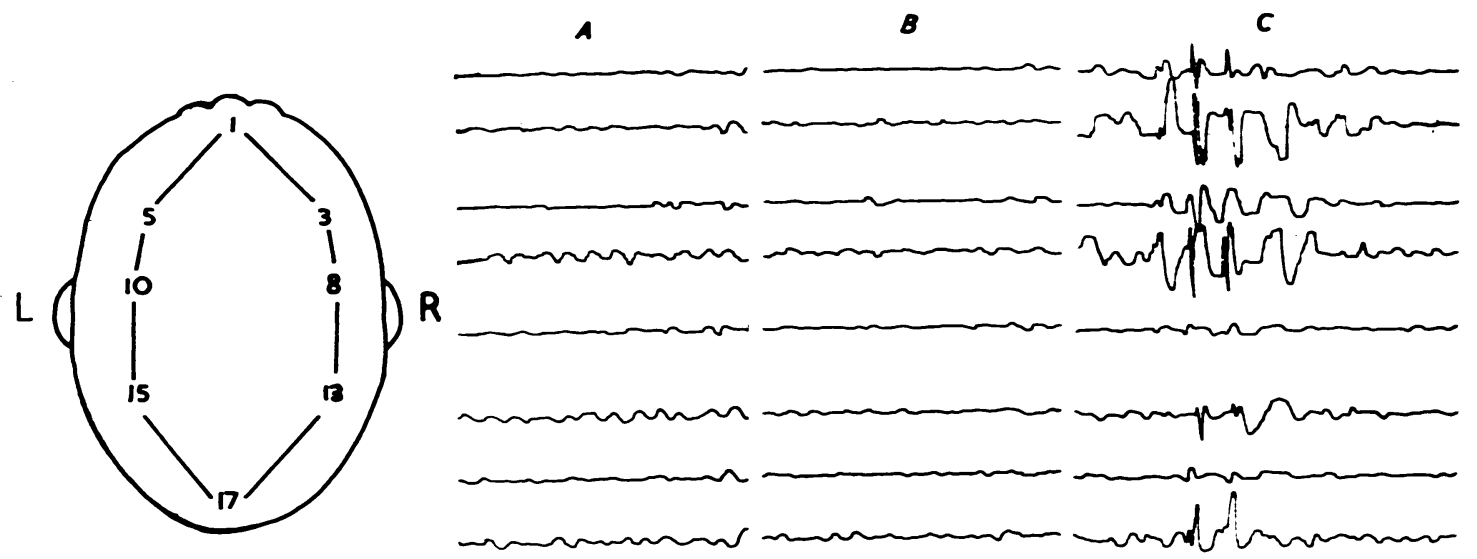

FIs. 3.-E.E.G. tracing on October 13, 1954. A shows asymmetry, B a flat record, and C spikes during an episode. Positions 1 and 2.

what was required of her. She had a low frustration tolerance and gave up easily. She worked for a short time with a test item, and, being faced with apparent failure, she appeared to become irritated by her inability to succeed. This was followed by a short temper tantrum, during which she pushed the items off the table on to the floor.

She reacted indifferently to praise. When she wanted to stop working on a test item, no amount of praise or encouragement was effective in keeping her at her task.

She was able to name objects, but was unable to explain their use. Vocabulary was extremely limited, spontaneous speech consisting of one or two-word sentences, often unintelligible. When asked to repeat sentences, responses consisted of 'unintelligible baby talk'.

An E.E.G. (Fig. 3) was done on October 13 and Dr. M. K. Wright reported that there was an area of diminished amplitude over the right central and parietal areas, and also a definite spike focus on the convexity of the left frontal lobe. Such spike foci commonly shift in young children. The E.E.G. suggested that there had been rather diffuse cortical damage rather than a localized lesion.

\section{Discussion}

The morbid anatomical findings following hypoglycaemic coma may be widespread, and Lawrence, Meyer and Nevin (1942) have indicated several different pathological changes. There may be complete necrosis of nerve cells over areas of the cerebral cortex and these areas may be remarkably circumscribed. In addition to the necrotic lesions there are areas of lesser damage in which cells are not completely destroyed. There may also be gross vascular lesions in the cortex and basal ganglia. Lawrence et al. (1942) compare these changes to the damage in the central nervous system following severe anoxaemia due to causes as dissimilar as poisoning with cyanide, carbon monoxide and ether, status epilepticus and cardiac arrest during anaesthesia. The two cases of Roche (1942), both of which came to necropsy, had cerebral changes; the first showed perivascular softening in the thalamus, caudate and lenticular nuclei, and the second a generalized softening, especially in the cerebellum. Hicks (1950), in animal experiments, showed that the administration of insulin to rats in dosages sufficient to cause convulsions often led to destruction of nerve cells of the cerebral cortex and corpus striatum; the basal nuclei were occasionally affected. Grayzel (1934) in experiments performed on rabbits found that in hypoglycaemic animals in which convulsions occurred brain damage was marked, whereas in rabbits in which the dose of insulin was insufficient to cause convulsions minimal or no microscopic evidence of necrobiosis was found. The brain damage in these patients is due to the fact that nerve cells require glucose for their oxidative processes. The cells, however, carry a very small reserve of glucose and have to replenish these stocks from the blood glucose. Thus, in cases in which the blood sugar level falls too low the cell metabolism becomes grossly impaired, resulting in severe damage to or actual death of the cell. The failure of this essential oxidative process leads to the final picture which is similar to that found in anoxic damage to the brain.

Tyler (1941), working with cats, found that the higher the dose of insulin the greater the brain damage, and that the giving of phenobarbitone tended to ameliorate the symptoms. In addition, cats at a low temperature tended to receive less damage to the central nervous system. Cerebral metabolism is depressed by both hypothermia and by the administration of barbiturates, leading to a lessened oxygen uptake, and therefore a lessened 
need of oxygen, which is obviously desirable in hypoglycaemia. The higher the dosage of insulin in these animals, the more protracted was the fall in blood sugar and the greater was the amount of glucose required to terminate the hypoglycaemia.

The symptoms of hypoglycaemia vary somewhat with the type of insulin used, but are basically the same for both short- and long-acting insulins. They commonly appear several hours after the administration of crystalline insulin, but may occur much sooner if the patient has taken no food or has had to take violent exercise in the interim. The longacting insulins-globin insulin, N.P.H., P.Z. insulin and the 'lente 'insulins-have their maximum effects later, the symptoms are less spectacular and the patient's attention is not drawn to them so readily. He slips quietly and unobtrusively into a stuporous state. The response to the administration of glucose by mouth or by intravenous injection is usually quick. It should, however, be remembered that long-acting insulins continue to act after the bloodsugar has been restored to normal and that frequent doses of sugar must be administered.

The difficulty encountered in our case in terminating the coma, despite adequate treatment, has been recorded elsewhere (Klein and Ligterink, 1940). The longer the patient has been in coma the more difficult it is to terminate the condition (Joslin, Root, White and Marble, 1952). Lawrence et al. (1942) state that coma of up to three hours is usually associated with complete recovery, while coma of longer duration is dangerous. Layne and Baker (1939) make the observation that the return of the blood sugar to normal has little effect on the duration of coma. It is important to maintain a normal or rather high blood sugar level during the state of recovery. In our case the observations of Klein and Ligterink (1940), Layne and Baker (1939) and Joslin et al. (1952) are well brought out; this child had a raised blood sugar level on admission to this hospital after having had intravenous glucose in the outside hospital. This is also in accord with the experimental evidence of Tyler (1941), who found that many of the cats used in his research work remained comatose for several days despite a normal blood sugar level.

Hypoglycaemic coma with cerebral damage may lead to progressive mental deterioration and to organic brain damage which may manifest itself clinically as paralysis or epilepsy. Anderson (1940) reports two cases. In one the child's mental age after the onset of coma at 13 years was $5 \frac{1}{2}$ years, and in the other child the mental age at 7 did not exceed 4 years. In the first case the child's memory improved, but the second patient had to be placed in an institution. Allan and Crommelin (1942) report a child, aged 6 years, in whom some degree of mental dullness remained months later. In several cases of hypoglycaemic coma reported by Graham (1950) (all adults) the patients had mental changes of a degenerative nature.

Klein and Ligterink (1940) report two cases of hypoglycaemic coma followed by mental retardation. Gardner and Reyersbach (1951) record a case of progressive mental deterioration following brain damage, despite the avoidance of further hypoglycaemia. Murphy and Purtell (1943) in reviewing 26 cases from the literature, eight of which died, record six instances of mental defect, and a further six cases described as personality changes, mental changes, organic psychosis, mental confusion and 'mental invalid'. Two children, one aged 8 and one aged 15, in a series of seven cases reported by Layne and Baker (1939) both showed mental retardation. The older child manifested epilepsy and was ataxic. Several of McQuarrie's (1954) cases of convulsions and coma due to spontaneous hypoglycaemia are mentally retarded and show damage in the central nervous system.

The organic changes may result in paralysis or epileptic seizures, and in all the cases quoted above either organic changes or convulsions occurred. Several cases in the literature, quoted by Murphy and Purtell (1943), were aphasic either permanently or temporarily, but it was not stated whether this was due to mental change or brain damage. In their own case they report mental change and temporary paralysis and the aphasia was obviously due to the mental condition.

The case of Gardner and Reyersbach showed a progressive deterioration in the E.E.G. and that child had convulsions which were extremely difficult to control; in addition, air studies showed definite enlargement of the lateral and third ventricles. In electroencephalographs done on 35 diabetic cases with repeated insulin reactions by Greenblatt, Murray and Root (1946) there were 18 definitely abnormal, nine borderline and eight normal. In our case the E.E.G. was abnormal and an air study showed enlargement of the right lateral ventricle.

The present state of our patient fits in well with the description of mental retardation, frequent epileptiform seizures and hemiplegia referred to by various authors. The convulsions as exhibited in our case are extremely difficult to control and consist of grand mal seizures, petit mal absences and akinetic attacks. The child's response to all forms of medication has been poor. The trigger mechanism, according to the parents, may be either hypoglycaemia or acidosis. Engel, Halberg, Ziegler and 
McQuarrie (1952), in very complete studies on two children with epilepsy following hypoglycaemic coma, found that no correlation could be determined between seizures and the blood sugar level. These authors showed that there is, however, less association of the spike-and-wave activity at $2 \frac{1}{2}$ per sec. with hypoglycaemia than with hyperglycaemia.

McQuarrie (1954) treated 25 cases of spontaneous hypoglycaemia with cortisone or corticotrophin with very good results. This was also done in our case, and in our opinion should be part of the treatment of similar patients in future, particularly in those cases caused by long-acting insulins.

In the light of the experimental work of Tyler (1941) these comatose patients should perhaps be sedated and subjected to hypothermia. The practical application and degree of hypothermia remain to be determined. It would appear physiological not to warm the patient, and it is possible that the warmth applied to our patient before her transfer to this hospital may have contributed towards the noxious effects of the hypoglycaemic state. In view of recent work on hypothermia during cardiac surgery, this treatment may possibly be tried in future cases. It must be noted that the cats in Tyler's experiments were not 'cooled', they were merely not 'warmed'. There was a drop in temperature of about $6^{-} \mathrm{C}$. in these animals by the time coma had set in, and this appeared sufficient to ward off a large degree of brain damage.

\section{Summary}

A case of hypoglaemic coma is recorded and the pathology discussed. The clinical observation is made that coma may persist for many days despite the restoration and maintenance of a normal blood sugar level. The final state of severe brain damage manifesting itself as convulsive episodes, mental defect and hemiplegia is described.

The literature is briefly discussed.

The suggestion is made that cortisone, sedation and hypothermia may be useful adjuncts in the therapy of this condition.

We would like to thank Dr. K. Mills, Medical Superintendent, the Johannesburg Group of Hospitals, and Dr. J. J. Theron, Assistant Visiting Paediatrician at the Transvaal Memorial Hospital for Children, for permission to record this case, Mr. S. Shevitz, of the Department of Medicine of the University of the Witwatersrand, for the radiographs, Dr. M. Wright for the E.E.G. tracings and reports, and Dr. S. Heymann, Head of the Department of Paediatrics, University of the Witwatersrand, for the interest he has taken in this paper.

\section{REFERENCES}

Allan, F. N. and Crommelin, R. M. (1942). J. Amer. med. Ass., 118, 373

Anderson, E. W. (1940). Lancet, 2. 329.

Engel, R., Halberg. F., Ziegler, $M$. and McQuarrie, I. (1952). J.-Lancet, 72, 242

Gardner, L. I. and Reyersbach, G. C. (1951). Pediatrics, 7, 210.

Graham, G. (1950). J. roy. Inst. publ. Hlth, 13. 302.

Grayzel, D. M. (1934). Arch. intern. Med., 54, 694.

Greenblatt, M., Murray, J. and Root, H. F. (1946). New Engl. med. $J ., 234,119$.

Hicks, S. P. (1950). Arch. Path., Chicago, 49, 111

Joslin, E. P., Root, H. F., White, P. and Marble, A. (1952). The Treatment of Diabetes Mellitus, 9th ed. Philadelphia.

Klein, F. and Ligterink, J. A. (1940). Arch. intern. Med., 65, 1085.

Klein, F. and Ligterink, J. A. (1940). Arch. intern. Med., 65, 1085.
Lawrence, R. D., Meyer, A. and Nevin, S. (1942). Quart. J. Med., 11, 181 .

Layne, J. A. and Baker, A. B. (1939). Minn. Med., 22, 771

MeQuarrie, I. (1954). Amer. J. Dis. Child., 87, 399.

Murphy. F. D. and Purtell. J. (1943). Amer. J. dig. Dis., 10. 103.

Roche. E. H. (1942). Brit. med. J., 2, 35.

Tyler. D. B. (1941). Amer. J. Physiol., 131, 554 